\title{
A Criminal Injustice System? Sex Offender Suspects and Defendants
}

\author{
Karen Corteen ${ }^{1} \cdot$ Rachael Steele $^{1}$
}

Published online: 10 October 2018

(C) The Author(s) 2018

\begin{abstract}
The purpose of this paper is to open up a discussion regarding the potential shift from the presumption of innocence to a presumption of guilt regarding those suspected of or charged with sexual offending. It is acknowledged that further investigation is needed and it is hoped that this discussion is one of many. The crux of this paper therefore is that sex offender suspects and defendants potentially find themselves in a criminal injustice system. Whilst the focus is predominantly on 'victims' (usually female) and people suspected or charged with sexual offending (usually male) within the criminal justice system in England and Wales the concerns articulated here are not confined to this context. For example such concerns are echoed in relation to the potential injustices occurring on American campuses. This demonstrates that this is a domestic and international situation and a situation that extends beyond the criminal justice system. We argue that what is occurring at home and abroad has to be contextualised with regard to public, media and official attitudes and approaches to 'victims', suspects, defendants, sex, sexual consent, sexual offending and a subsequent shift from the presumption of innocence to a presumption of guilt. It is argued that not only is the presumption of innocence undermined by the presumption of guilt regarding suspects and defendants in cases of sexual offending, it is also undermined in England and Wales by the victim personal statement (VPS). The VPS contains and promotes the idea that there is a 'victim' and 'offender' before this has been legally established in a court of law. These assumptions embodied within the VPS weaken the principle and practice of the presumption of innocence. The safeguard of the presumption of innocence is potentially under threat and the result is an even greater potential for miscarriages of justice and wrongful convictions.
\end{abstract}

Rachael Steele

R.H.Steele@1jmu.ac.uk

Karen Corteen

K.M.Corteen@1jmu.ac.uk

1 School of Law, Liverpool John Moores University, Redmonds Building, Brownlow Hill, Liverpool L3 5UG, UK 
Keywords Suspects rights $\cdot$ Sexual offending $\cdot$ Injustice $\cdot$ Victim personal statement

\section{Introduction}

... claims to be 'rebalancing the system' in favour of victims call for close scrutiny in a country with such an unfortunate record of miscarriages of justice. $^{1}$

Injustice anywhere is a threat to justice everywhere. ${ }^{2}$

At the outset it is important to state that much literature on sexual offending focuses on the issue of rape and the 'justice gap'. Levels of attrition in rape cases remain a concern, and the impact of 'rape myths', victim-blaming attitudes, gender stereotypes and the reliability, and credibility of complaints and defendants are important considerations in attrition. ${ }^{3}$ We agree that these are sensitive and important considerations. ${ }^{4}$ The concern here however, is the potential wrongful conviction and miscarriages of justice regarding those suspected of or charged with a sexual offence. This is due to cultural changes inside and outside the criminal justice system. Wrongful conviction and miscarriages of justice can be simply understood "as the wrongful conviction of a factually innocent person that did not commit the crime they were convicted of and played no part at all in it". Naughton highlights that "every single day, people are overturning convictions for criminal offences. Miscarriages of justice are a routine, even mundane feature of the criminal justice system. They are systemic". ${ }^{6}$ Over the past twenty years there have been clear classes of miscarriages of justice including historical sexual abuse cases. ${ }^{7}$ Many common law jurisdictions, have witnessed an increased interest in and concerns about the problem of wrongful convictions and miscarriages of justice. ${ }^{8}$ This is over the past few decades and the interest and concern is both on the part of the public and scholarly researchers. This is due to the exposure of high profile miscarriages of justice which have brought to light problems in the way that the criminal justice system works. Despite reforms being made in the criminal justice system in light of such concerns miscarriages of justice and wrongful convictions continue to happen. ${ }^{9}$ We are concerned with potential miscarriages of justice and wrongful convictions regarding those suspected or charged with sexual offending. This has to be contextualised.

\footnotetext{
1 Ashworth (2006, p. 243).

2 Martin Luther King, JR cited in False Allegations Support Organisation (FASO) (2018).

3 See Saunders (2018) for more detail.

4 Saunders (2018).

5 Huff and Naughton (2017, p. 1).

${ }^{6}$ Cited in Goldhill (2014).

7 Robins (2018).

8 Huff and Naughton (2017).

${ }^{9}$ Naughton (2016), Robins (2018).
} 
In the last 20 years or so in many Western countries the nature of sexual offending and responses to it have become prioritised ${ }^{10}$ within the criminal justice system and societally. This includes the introduction of the Sexual Offences Register in 1997 in England and Wales. Thomas ${ }^{11}$ comments, "[a]ttempts have been made to improve the prosecution and conviction rate of those who commit sexual offences and sentences have become more punitive". The criminal justice system is therefore under pressure from within and without the to improve investigations, prosecutions and convictions of suspects of sexual offending. This is happening at home and abroad in which the current climate is saturated with public reports and visual representations of, and campaigns against, sexual misconduct. This includes the public reporting of cases of historical abuse on the part of celebrities, child victims of grooming and sexual abuse, student campaigns against sexual violence such as RevoltSexualAssault, and the \#MeToo Movement. In such an emotive climate it is important to remember the rights of suspects, defendants and those convicted of an offence as well as those of accusers, complainants and witnesses. This is because the conviction of an innocent person is the highest injustice. Therefore, in an adversarial system that upholds the principle of due process, there are safeguards that are intended to protect suspects and defendants, including individuals' accused of a sexual offence(s). However the presumption of innocence "has been under heavy fire over the last two decades from ambitious politicians and a press quick to be outraged, but reluctant to understand". ${ }^{12}$ This is to the extent that for Hayler ${ }^{13}$ "the increasing focus on convicting the guilty instead of protecting the innocent means that we may soon all have cause to fear the dawn raid". We argue that the safeguard of the presumption of innocence is currently being potentially undermined regarding sexual offending and the outcome is miscarriages of justice and wrongful convictions. We appreciate that further investigation is needed however we intend to open up a discussion of the potential contemporary shifts in the manner that sexual offences are viewed and responded to within and without the criminal justice system and what this may mean for those suspected of and charged with sexual offending. In so doing we discuss the presumption of innocence and then we show how this may be undermined due to recent concerns about a retreat from this principle even to the point where there are fears of a presumption of guilt with regard to sex offences. ${ }^{14}$ We also demonstrate the role played by the pressure to believe the accuser of sexual misconduct inside and outside the criminal justice system. We then go on to discuss how the victim personal statement (VPS) contains inherent assumptions that also undermine the presumption of innocence. Finally some conclusions are provided.

\footnotetext{
10 Thomas (2014).

11 Thomas (2014, p. 267).

12 Hayler in Robins (2018, p xii).

13 Ibid.

14 Davies (2016).
} 


\section{The Threat to the Presumption of Innocence and the Pressure to Believe}

The threats to defendants' rights have already been articulated. ${ }^{15}$ Many individuals in the criminal justice system "frequently slip into talking of victims (in trials), rather than witnesses" 16 or accusers or complainants. In some cases outside the criminal justice system on American campuses accusers are also referred to as "survivors' and the campus mantra is "'Survivors must be believed". ${ }^{17}$ Also for some groups in the criminal justice system, "[t]hose who plead not guilty are accused of 'gaming the system'", and the aim of the criminal justice system is "to get all those accused of crimes to plead guilty... as early as possible" and this is perceived as "good performance" on the part of such individuals. ${ }^{18}$ It has also been contended that police attitudes are still leading to damaging mistakes, incomplete investigations and non-disclosure of evidence. ${ }^{19}$ This leads to an unfair criminal justice system and subsequently a lack of confidence in the system on the part of accusers/ victims and defendants/offenders. ${ }^{20}$ In the current climate there is the pressure and even "the requirement to believe the complainant" and this results in an "incomplete investigation, and an incomplete investigation is a threat to the whole process of justice". ${ }^{21}$ The above criticisms go against the wider sense of the presumption of innocence embodied in European human rights law in that "pre-trial procedures should be conducted, so far as possible, as if the defendant were innocent". ${ }^{2}$

A clear example of an "[i]ncompetent [p]olice [i]nvestigation" is that of Warren Blackwell. ${ }^{23}$ Warren Blackwell had his conviction overturned in 2006 "after a sevenyear battle to clear his name" (Ibid). Shannon Taylor accused Blackwell of attacking her outside a social club. Blackwell was convicted of sexual assault in 1999 but after being imprisoned for three years his conviction was overturned as Taylor's history of making false allegations of sexual assault under another name came to light. ${ }^{24}$ After Blackwell won his appeal, a series of errors that contributed to Blackwell's wrongful conviction on the part of Northamptonshire Police were identified by the Independent Police Complaints Commission. A police officer from another force had expressed his concerns that "Taylor's evidence bore striking similarities with other false allegations" that she had made-but these were ignored ${ }^{25}$ Further, in a detectives notes Taylor was described as 'unreliable' and 'unstable' however they

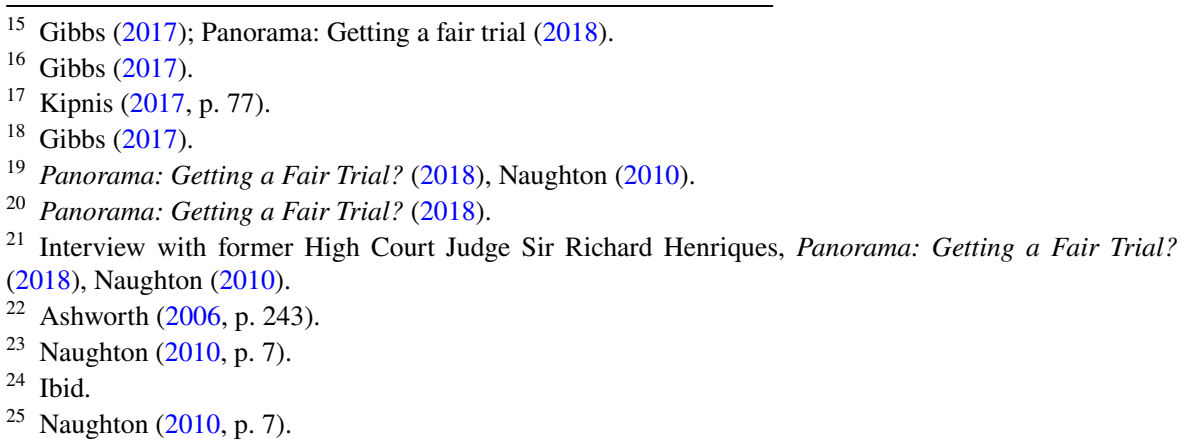


were not passed on to the Crown Prosecution Service. Finally, Taylor's accounts contained serious inconsistencies and the police insufficiently investigated them. ${ }^{26}$ Another example of a false allegation that resulted in prison sentences of 18 years and 11 years are that of George Anderson and Margaret Hewett. One of the complainants admitted that they had lied, and this resulted in Anderson and Hewett's convictions being over turned. ${ }^{27}$

The potential for injustice and the threat to the presumption of innocence is not just confined to problems with police attitudes and police investigations it can also be evidenced in the criminal trial. The safeguards that are in place to ensure a fair trial are put to the test in the courtroom. The courtroom is the decisive stage in which a defendant is either found guilty or acquitted. In so doing the prosecution has to make a case that demonstrates that the defendant is guilty beyond reasonable doubt. This is because according to the adversarial system a defendant is presumed innocent of the case laid against them until a guilty verdict is reached. This is one of, if not the most, important procedural protections afforded to defendants. This is especially so with regard to the potential loss of liberty, in the form of imprisonment. In addition there are social consequences that arise from being convicted. These can include "stigma and disadvantages in employment and housing". ${ }^{28}$ Plus for individuals convicted of a sexual offence they have the legal consequence of 'notification requirements'. Importantly one of the worst forms of victimisation has been identified as serving a prison sentence without having committed a crime. ${ }^{29}$

According to the Community of the Wrongly Accused 30 "accusations of serious criminality, especially alleged sexual wrongdoing, are often their own convictions in the court of public opinion". This means that the public assumes that an allegation of a sexual wrongdoing must be true, and therefore the public jumps to the conclusion that once a person is accused of a sexual offence(s) that person will be convicted of such. This is due to the severity of the social stigma surrounding sexual wrongdoing together with the difficulties in proving the innocence of the person being accused. ${ }^{31}$ The presumption of guilt is also nurtured by some of the aims and values embedded within the criminal justice system. For example, in 2002, the Metropolitan police stated that officers should "accept allegations made by the victim in the first instance as being truthful". 32 This was compounded by a 2005 report that called for the institutionalisation of a "culture of belief, support and respect" regarding victims of sexual offences. ${ }^{33}$ Finally in 2014, Her Majesty's Inspector of Constabulary asserted "[the] presumption that a victim should always be believed should be institutionalised" and that complaints of sexual abuse have to be recorded as a crime straight

\footnotetext{
26 Ibid.

27 See Naughton (2010) for more detail.

28 Ashworth (2006, p. 243).

29 Sarnoff in Hoyle et al. (2016).

${ }^{30}$ Community of the Wrongly Accused, https://olbios.org/the-community-of-the-wrongly-accused.

31 Ibid.

${ }^{32}$ Hogan-Howe (2016, paragraph 11).

33 Hogan-Howe (2016, paragraph 11).
} 
away. ${ }^{34}$ If rather than testing the evidence with an open mind the accuser is to be automatically and unconditionally believed then the accused may potentially be presumed to be guilty of the alleged offence. This illustrates that the presumption of guilt regarding individuals suspected of a sexual offence is a real problem, and this can persist despite the lack of judicial conviction either pre trial, where no prosecution subsequently takes place, or even where a trial does take place and a defendant is found not guilty. In the current climate of (rightly) supporting and empowering victims it can seem that even "questioning the veracity of allegations can be seen as a betrayal of the victim". ${ }^{35}$ As research into the voice of the victim has gained rightful and necessary traction ${ }^{36}$ there has been a cultural shift inside and outside of the criminal justice system towards an automatic belief of accusers of abuse. While it is extremely important to continue to empower victims to speak up about their experiences, the engendered "moral imperative not to "let down another victim", 37 is a threat to the impartiality of the courtroom, and the premise of innocent until proven guilty on which the judicial system operates. This is significant as the consequences of the presumption of guilt can be severe, affecting not only the judicial sentencing of the accused but also the moral or social sentence that many defendants find themselves labouring under even in the absence of formal prosecution.

The presumption of guilt and a climate of unquestioning belief in accusers' narratives are not confined to England, Wales, and the criminal justice system. Kipnis ${ }^{38}$ for example in her book discusses a collective culture of rape and sexual paranoia on American campuses and subsequent "officially sanctioned hysteria". ${ }^{39}$ In a newspaper interview about her book she also states that inside and outside of American campuses there is the idea that sex is "inherently injurious" and this "ethos of injury creates injury. It's self-fulfilling". ${ }^{40} \mathrm{Kipnis}^{41}$ comments on how future generations will retrospectively look back at this situation and "wonder how supposedly rational people could have succumbed so easily to collective paranoia" and "how the federal government got into the moral panic business, tossing constitutional rights out of the window in an ill-conceived effort to protect women students from a rapidly growing catalogue of bogeymen".

Kipnis ${ }^{42}$ found herself the subject of a student protest, an official complaint, and a 72 day institutional investigation as a result of writing an essay concerned with sexual paranoia on campus. Despite the denial of a lawyer and being able to record her sessions with the investigators, and learning the charges against her when she was sat in from of them, thus having no time to prepare, she fought and won the case. As a result of this Kipnis decided to write a whistle-blowing essay on her experience. In

\footnotetext{
34 Ibid.

35 Hoyle et al. (2016, p. 20).

36 Hoyle (2012).

37 Hoyle et al. (2016, p. 4).

38 Kipnis (2017).

39 Kipnis (2017, p. 1).

40 See Cooke (2017, paragraph 22).

41 Kipnis (2017, p. 1).

42 Kipnis (2017).
} 
so doing she discovered a new norm on contemporary American campuses of "rampant accusation" "especially when it comes to sex". ${ }^{43}$ She also unearthed a hidden world of "tales of overblown charges, capricious verdicts, and frightening bureaucratic excess" together with "accused professors and students, rigged investigations, closed-door hearings" and investigating officers running amok. ${ }^{44}$ Kipnis acknowledges that on campus sexual assault is a reality and that everyone shares the goal of addressing this. However, she fears that the prioritisation of stories concerned with female endangerment over female agency "are the last thing in the world that's going to reduce sexual assault". ${ }^{45}$ In fact this standpoint is at the heart of Kipnis's central argument.

In reality sex is "muddled" and "confusing". ${ }^{46}$ Kipnis $^{47}$ highlights the messiness and complexities of sexual realities and this of course muddies the waters regarding sexual consent and accusations of sexual misconduct. 'Consent' is a concept that is "cloudy" and "subject to change". ${ }^{48}$ Kipnis comments that, "[y]ears later, sex that was consensual can apparently become non-consensual. I think that is quite shocking and it should be known". ${ }^{49}$ Kipnis is concerned that amidst the reality of sexual messiness and complexity, a focus on women's vulnerability and endangerment, together with a protectionist and paternalistic agenda may result in accusations of sexual offences or sexual misconduct being alleged as a result of poor sexual choices, "awkward sexual experiences or sexual ambivalences, and to adjudicate relationship disputes post-breakup". Indeed she contends that, "campus administrators are allowing it". ${ }^{50}$ In a climate of rampant allegation and a presumption of guilt this is a dangerous and harmful situation as accused individuals (professors or students) may be left with a tarnished reputation at best, and expulsion from campus with no future prospects at worse. Furthermore, confusion around the issue will only serve to obfuscate and confuse genuine victims of sexual abuse and assault, those individuals who in fact, the system exists to protect and support.

Just as the presumption of guilt has become a cultural imperative, it has had practical applications within the courtroom. Studies show clearly that where a presumption of guilt exists, it affects what a juror perceives about the accused and the accuser, and becomes subject to a behavioural confirmation bias in which aspects of speech, body language and characteristics influence jurors' thinking. ${ }^{51}$ A cultural or 'moral imperative' 52 to believe the accuser of sexual misconduct or abuse can lead to a 'generic prejudice' against that category of offender, that is, a general belief

\footnotetext{
43 Kipnis (2017, p. 6).

44 Ibid.

45 Kipnis (2017, p. 8).

46 Cooke (2017, paragraph 21).

47 Kipnis 2017).

48 Cooke (2017, paragraph 21).

49 Ibid.

50 Kipnis (2017, p. 17).

51 Kasin et al. (2003).

52 Hoyle et al. (2016).
} 
about those accused of similar crime with concurrent biases. ${ }^{53}$ These biases may mean that the testimony of the accused is viewed less favourably than the testimony of the accuser-again, leading to problems in how the victim voice can adequately be expressed without undue influence on those making decisions on guilt. Likewise, studies show that media portrayal of victims (whether related to a specific case or to similar cases) can also affect jury decision-making. Where victims are portrayed in a generally positive light—using adjectives such as 'kind' or 'likeable' jurors are significantly more likely to find the accused guilty. ${ }^{54}$ There is of course, research that clearly suggests that these cognitive biases operate within the minds of jurors in the other direction - that is, that some juror may hold victim blaming attitudes, or beliefs that are influenced by rape myths. ${ }^{55}$ However, in accepting that cognitive bias exists, consideration must be given to the impact of this bias, and how this may be influenced by the emerging change of focus to a "culture of belief, support and respect" regarding victims of sexual offences. ${ }^{56}$

The upholding of the principle of the presumption of innocence is not a panacea to miscarriages of justice and wrongful convictions. Indeed, in reality it may act "against the interests of those who might be innocent at every stage of the criminal justice process". 57 This is because not only does this 'presumption' make suspects and defendants passive, it also means that pressure is put on the police and prosecution "to chip away at the presumed innocent status and construct cases that might obtain a conviction, rendering innocent victims vulnerable to wrongful convictions". ${ }^{58}$ However, whilst in practice the presumption of innocence may be problematic, it remains one of the most important principles and potential safeguards with regard to suspects and defendants of sexual offending. This is especially so within a criminal justice system where jurors are anxious not to "let down another victim". 59

\section{The Victim Personal Statement}

In most common law countries, individuals who report a crime to the police have the opportunity to have some input into the criminal process by way of the provision of impact evidence on their part. ${ }^{60}$ In England and Wales this impact evidence takes the form of a victim personal statement (VPS). Elsewhere this is known as a victim impact statement (VIS). ${ }^{61}$ In England and Wales the police take the VPS and this is

\footnotetext{
53 Kramer et al. (1990).

54 Bane and Flynn (2018).

55 E.g. Smith and Skinner (2017).

56 Hogan-Howe (2016, paragraph 11).

57 Naughton (2011, p. 40).

58 Ibid.

59 Hoyle et al. (2016, p. 4).

60 Roberts and Manikis (2012).

61 See Pemberton and Raynaers (2011) for a discussion of how the VIS affects the impartiality of the trial, and puts pressure on the rights of suspects and on criminal justice principles such as proportionality and due process.
} 
included in the prosecution papers. The 'victim' is offered the opportunity to make a VPS in their first contact with the police and they can make it anytime up to the sentence. The 'victim' may not change it but they can add to it and they can make more than one VPS. Everyone involved in the case should read the VPS. Since 2013, if the court permits (which they usually do) 'victims' can have their VPS heard in court once the defendant has pleaded or been found guilty. This is in order to ensure that all parties are made aware of the impact of crime on the 'victim'.

There are many problems inherent within the VPS that undermine the presumption of innocence regarding the defendant, not least that the attention is fundamentally shifted from the burden of proof on the part of the prosecution, to the harm experienced by the victim. ${ }^{62}$ The VPS takes for granted that there is a 'victim' and 'offender' before this has been established procedurally by a guilty verdict. Davies ${ }^{63}$ a former senior crown prosecutor observes " $[\mathrm{w}] \mathrm{e}$ know the person giving evidence is complaining; we do not know whether she is a 'victim' until she has given her evidence and been through cross-examination and the defendant has given his own account of what happened". The VPS is taken at a stage in the process where there is an accuser and an accused. Yet the accuser is treated like an established crime victim in that they can: ask for additional support (particularly when giving evidence); state the impact of the 'crime' on them; articulate fears regarding the 'offender' getting bail; highlight potential motivations for the 'crime' with regard to racial hostility, faith, cultural background and disability, and state if they wish to apply for compensation and protective measures if the case goes to court. The accused is assumed to be guilty as within the VPS they are referred to and treated as the 'offender', from the viewpoint of the 'victim' and in reference to the criminal justice process.

This is especially problematic in England and Wales as the influence of the VPS goes beyond impact evidence during the sentencing process. Victim impact schemes in other common law jurisdictions confine the use of VIS to the sentencing process. But in England and Wales "the VPS is meant to be used at various stages of the criminal justice process, including during the decision by the CPS whether or not to prosecute, the decision to grant bail and so on". ${ }^{64}$ Thus the VPS is used in the criminal justice system decision-making process from arrest through to the prosecution process before the legal establishment of a victim and offender. While it is extremely important to allow victims to participate in the criminal justice process, the content of the VPS or the VIS is more than a simple statement of experiences or facts. As suggested above, it cements for the court the victim/offender relationship of the two individuals in court - a far stronger scenario for a juror struggling to process facts and evidence than an 'accuser' and 'defendant'. The VIS is a "symbolically charged narrative" 65 which provokes an empathic and emotional response. For a juror exposed to such a narrative, the presumption of innocence of the defendant may feel akin to a denial of the content of the victim testimony.

\footnotetext{
62 Kramer et al. (1990).

63 Davies (2016).

64 Roberts and Manikis (2012, p. 248).

65 Joh (2000, p. 22).
} 
For all these reasons, the undermining of the principle of 'innocent until proven guilty' in the VPS impacts on all defendants whose accuser takes up this opportunity. But this is especially significant for individuals accused of a sexual offence(s) as the VPS establishment of a 'victim', 'offender', 'crime', 'victimisation' and motivation for the offence, is potentially compounded by the presumption of guilt in cases of sex offending. Being believed when reporting a sexual offence is necessary and long overdue, and concerns regarding securing justice for victims of sexual offences have rightly been aired. ${ }^{66}$ However, it is also right to articulate and air concerns about the potential and real ramifications for criminal injustice with regard to those accused of a sexual offence(s). This is especially so, as "definitively proving innocence in a disputed sex case is often impossible". ${ }^{67}$ The accuser faces many obstacles and disadvantages when trying secure justice in sex cases, but so too do the accused. These are exacerbated by the pressures on juries to believe the accuser, the presumptions embedded in the VPS, and the presumption of guilt with regard to those accused of a sexual offence(s). We therefore challenge the assumption that the 'scales of justice' are massively tipped in favour of the accused. ${ }^{68}$ We argue that there is a real possibility that in cases concerned with allegations of sexual offences that in reality the opposite is true.

\section{Conclusions}

It is better that ten guilty persons escape than that one suffer. ${ }^{69}$

The concern with the victim voice and the rightful endeavour to achieve justice for victims needs also to be applied to those who are accused-and who in some cases may not actually be guilty. This is important within and without the criminal justice system as in these cases, individuals who are accused of sexual misconduct may be subject to a moral or social (or indeed legal) conviction based entirely on a false allegation. The 'former' accused individual is then left without support to try and cope, along with their families, with the fall-out of the impact of the social presumption of guilt on home life, employment, housing and so forth. Hoyle et al. ${ }^{70}$ argue that there is a justification for a victimological perspective on the "predicament of the falsely accused" and how the phenomenon of moral and social conviction impacts those who have been found by the judiciary to be innocent. This can be extended to falsely accused individuals in other contexts such as on University campuses and in other professional occupations were individuals are in a position of trust.

The very presumption of innocence exists (in principle at least) to avoid the "deep injustice and substantial moral harm" of the wrongful conviction of an innocent

\footnotetext{
66 Smith (2016), Spencer et al. (2018).

67 Community of the Wrongly accused, https://olbios.org/the-community-of-the-wrongly-accused.

68 Smith (2016).

69 William Blackstone's formulation cited in Naughton (2011, p. 41).

${ }^{70}$ Hoyle et al. (2016, p. 6).
} 
person. ${ }^{71}$ Safeguards within the criminal justice system for those who have been unjustly accused should not be removed, yet over time "governments have sought to load the dice against defendants in sex cases" ${ }^{72}$ The criminal justice system in England and Wales generally is "in a state of permanent crisis" and "inefficiency has become endemic". ${ }^{73}$ Also "the criminal justice pendulum has swung dramatically in the direction of victims' rights and away from the rights of defendants" and the dramatic cuts in legal aid mean that the legal representation of many defendants is incompetent. ${ }^{74}$ Furthermore there is "no adequate safety net" as "[t]he Court of Appeal continues to fail to get to grips with miscarriages of justice". ${ }^{75}$ In addition, for individuals enduring a miscarriage of justice or wrongful conviction, the Criminal Cases Review Commission is overwhelmed, chronically underfunded and ineffective and it does not do what it was set up to do-namely act as the "first state-funded miscarriage of justice watchdog". ${ }^{76}$ Given this and the current climate regarding the revelations and ramifications of public cases and campaigns regarding sexual offences the safeguard of the presumption of innocence must be upheld in both principle and practice. The focus should not be one of belief with regard to the accuser, but one where allegations of crime including sexual offences are taken seriously. Both accusers and accused should be subjected to a thorough, civilised investigation in which all relevant information and evidence claimed to indicate guilt is disclosed and subjected to critical interrogation. ${ }^{77}$ In light of this, if there is a case to answer, the accused should be given a fair hearing from start to finish. This includes being guided by the principle of innocent until proven guilty in the pre-trial and criminal trial stages. Seeking to safeguard the innocence of the accused does not in any way negate the experiences of harm caused to the victim, or imply that all accusers are insincere. Instead, this safeguard recognises that the harms may be severe, but there is also the small chance that in some cases they did not occur, and importantly, that where they did occur that the accused person may not be the perpetrator of those harms. The punishment of an innocent person (by the criminal justice system or any other regulatory body) victimises that person and in the criminal justice context, it results in a miscarriage of justice and the wrongful conviction of individuals' accused of sexual offending. Finally and crucially, the punishment of an innocent person is of no benefit to victims or society, as such a wrongful conviction potentially leaves the actual perpetrator at large.

Acknowledgements Thanks to Gary Wilson, Editor of Liverpool Law Review for his support in the publication of this article. Thanks also to the two anonymous reviewers for their constructive comments, they helped to strengthen this article.

\footnotetext{
71 Ashworth (2006, p. 247).

72 Davies (2016).

73 Robins (2018, p. xiii).

74 Robins (2018, p. xv).

75 Robins (2018, p. xxi).

76 Robins (2018, p. xix).

77 Naughton (2011).
} 


\section{Compliance with Ethical Standards}

Conflict of interest On behalf of all authors, the corresponding author states that there is no conflict of interest.

Open Access This article is distributed under the terms of the Creative Commons Attribution 4.0 International License (http://creativecommons.org/licenses/by/4.0/), which permits unrestricted use, distribution, and reproduction in any medium, provided you give appropriate credit to the original author(s) and the source, provide a link to the Creative Commons license, and indicate if changes were made.

\section{References}

Ashworth, A. 2006. Four threats to the presumption of innocence. The International Journal of Evidence and Proof 10: 241-279.

Bane, E., and Flynn, S. 2018. An investigation into the effects of victim-focused pre-trial publicity on juror decision-making. Poster presentation at British Psychological Society: Division of Forensic Psychology, Newcastle 19th June 2018.

Cooke, R. 2017. Sexual paranoia on campus-And the professor at the eye of the storm. The Observer 2 April. https://www.theguardian.com/world/2017/apr/02/unwanted-advances-on-campus-us-unive rsity-professor-laura-kipnis-interview. Accessed 28 Sept 2018.

Community of the Wrongly Accused n.d. Crime and public order-Politics: The community of the wrongly accused. https://olbios.org/the-community-of-the-wrongly-accused/. Accessed 29 Sept 2018.

Crown Prosecution Service. 2017. Victim personal statements. https://www.cps.gov.uk/legal-guidance/ victim-personal-statements. Accessed 28 Sept 2018.

Davies, J. 2016. Rape: The presumption of guilt. Quadrant Online 6 December. https://quadrant.org.au/ magazine/2016/11/rape-presumption-guilt/. Accessed 28 Sept 2018.

False Allegations Support Organisation (FASO). 2018. FASO - False Allegations Support Organisation. http://www.false-allegations.org.uk/news/. Accessed 28 Sept 2018.

Gibbs, P. 2017. Those who plead not guilty are not 'Gaming the System'. Centre for Crime and Justice Studies 3 April. https://www.crimeandjustice.org.uk/resources/those-who-plead-not-guilty-are-notgaming-system. Accessed 28 Sept 2018.

Goldhill, O. 2014. When innocent men go to jail: Miscarriages of justice in Britain. The Telegraph 4 September. https://www.telegraph.co.uk/news/uknews/law-and-order/11075284/When-innocent-mengo-to-jail-miscarriages-of-justice-in-Britain.html. Accessed 28 Sept 2018.

Hogan-Howe, B. 2016. Suspected sex offenders have rights the police must respect. The Guardian 10 February. https://www.theguardian.com/commentisfree/2016/feb/10/accused-sex-crimes-anony mous-until-charged-reputations-police-complaint. Accessed 28 Sept 2018.

Hoyle, C. 2012. Victims, victimisation and restorative justice. In The Oxford handbook of criminology, eds. M. Maguire, R. Morgan, and R. Reiner, 5th ed. Oxford: University Press.

Hoyle, C., Speechley, N., and Burnett, R. 2016. The impact of being wrongly accused of abuse in occupations of trust: Victims' voices. University of Oxford. https://www.law.ox.ac.uk/sites/files/oxlaw/ summary_report-_the_impact_of_being_wrongly_accused_of_abuse_hoyle_et_al_2016_15_may. pdf. Accessed 28 Sept 2018.

Huff, C.R., and M. Naughton. 2017. Wrongful conviction reforms in the United States and the United Kingdom: Taking stock. In Current problems of the penal law and criminology, ed. E.W. Plywaczewski and E.M. Guzik-Makaruk, 1-20. Joanna Ablewicz: University of Bialystok.

Joh, E. 2000. Narrating pain: The problem with victim impact statements. Southern California Interdisciplinary Law Journal 10(17): 17-37.

Kasin, S., C. Goldstein, and K. Savitsky. 2003. Behavioural confirmation in the interrogation room: On the dangers of presuming guilt. Law and Human Behaviour 27(2): 197-203.

Kipnis, L. 2017. Unwanted advances: Sexual paranoia comes to campus. New York: Harper Collins Publishers. 
Kramer, G., N. Kerr, and J. Carroll. 1990. Pretrial publicity, judicial remedy and jury bias. Law and Human Behaviour 14(5): 409-438.

Naughton, M. 2010. Claims of innocence: An introduction to wrongful convictions and how they might be challenged. Bristol: University of Bristol.

Naughton, M. 2011. How the presumption of innocence renders the innocent vulnerable to wrongful convictions. Irish Journal of Legal Studies 2(1): 40-54.

Naughton, M. 2016. Miscarriages of justice, wrongful convictions and victims. In A companion to crime, harm \& victimisation, ed. K. Corteen, S. Morley, P. Taylor, and J. Turner, 136-138. Bristol: Policy Press.

Panorama: Getting a Fair Trial? [TV Programme] BBC 30 April 2018. https://www.bbc.co.uk/iplayer/ episode/b0b228hf/panorama-getting-a-fair-trial. Accessed 28 Sept 2018.

Roberts, J.V., and M. Manikis. 2012. Victim personal statements in England and Wales: Latest (and last) trends from the Witness and Victim Experience Survey. Criminology and Criminal Justice 13(3): 245-261. https://doi.org/10.1177/1748895812452281.

Robins, J. 2018. Guilty until proven innocent. London: Biteback Publishing.

Pemberton, A., and S. Raynaers. 2011. The controversial nature of victim participation: Therapeutic benefits in victim impact statements. In Therapeutic jurisprudence and victim participation in justice, ed. E. Erez, M. Kilching, and J. Wemmer, 229-248. North Carolina: Carolina Academic Press.

Saunders, C.L. 2018. Rape as 'one person's word against another's': Challenging the conventional wisdom. The International Journal of Evidence \& Proof 22(2): 161-181.

Smith, A. 2016. They think they've got away: How to catch a historical sex offender. BBC News Online 20 June. http://www.bbc.co.uk/news/uk-england-nottinghamshire-36055744. Accessed 28 Sept 2018.

Smith, O., and T. Skinner. 2017. How Rape Myths Are Used and Challenged in Rape and Sexual Assault Trials. Social and Legal Studies 26(4): 441-466.

Spencer, D., A. Dodge, R. Ricciardelli, and D. Bullucci. 2018. "I think it's re-victimising victims almost every time": Police perceptions of criminal justice responses to sexual violence. Critical Criminology 26: 189-209.

Thomas, T. 2014. Sexual offending. In A companion to criminal justice mental health \& risk, ed. P. Taylor, K. Corteen, and S. Morley, 266-268. Bristol: Policy Press. 